\title{
Research Article \\ Effect of Graphene Oxide-Boron Nitride-Based Dual Fillers on Mechanical Behavior of Epoxy/Glass Fiber Composites
}

\author{
V. Kavimani $\mathbb{D}^{1}{ }^{1}$ P. M. Gopal $\mathbb{D},{ }^{1}$ B. Stalin $\mathbb{D}^{2},{ }^{2}$ Alagar Karthick $\mathbb{D},{ }^{3}$ S. Arivukkarasan, ${ }^{4}$ \\ and Murugesan Bharani iD $^{5}$ \\ ${ }^{1}$ Center for Material Science, Department of Mechanical Engineering, Karpagam Academy of Higher Education, Coimbatore, \\ 641021 Tamilnadu, India \\ ${ }^{2}$ Department of Mechanical Engineering, Anna University, Regional Campus Madurai, Madurai, 625019 Tamilnadu, India \\ ${ }^{3}$ Department of Electrical and Electronics Engineering, KPR Institute of Engineering and Technology, Coimbatore, \\ 641407 Tamilnadu, India \\ ${ }^{4}$ Department of Mechanical Engineering, SACS MAVMM Engineering College, Madurai, 625301 Tamilnadu, India \\ ${ }^{5}$ School of Textile Leather and Fashion Technology Kombolcha 208, Kombolcha Institute of Technology, Wollo University, \\ South Wollo, Ethiopia
}

Correspondence should be addressed to Murugesan Bharani; bharani.murugesan@kiot.edu.et

Received 5 May 2021; Accepted 21 July 2021; Published 9 August 2021

Academic Editor: Ashish R Tanna

Copyright ( 2021 V. Kavimani et al. This is an open access article distributed under the Creative Commons Attribution License, which permits unrestricted use, distribution, and reproduction in any medium, provided the original work is properly cited.

\begin{abstract}
Graphene and its derivatives have excellent properties such as high surface area, thermal, and mechanical strength, and this fact made the researchers promote them as the possible filler material for fiber-matrix composite. The current research deals with validation on the effect of graphene oxide boron nitride filler over mechanical and thermal stability of epoxy glass fiber polymer matrix composite. The objective of this experimental investigation is to develop glass fiber reinforced polymer composites with hybrid filler addition. The matrix material selected is epoxy resin, whereas the glass fiber is selected as reinforcement, while boron nitride and graphene oxide are chosen as fillers. Compression moulding methodology is followed to develop the composites with the constant percentage of fiber loading, graphene oxide filler, and varying boron nitride content from 0 to $3 \mathrm{wt} . \%$ at an equal interval of $1 \mathrm{wt} . \%$. The developed composite is analyzed for mechanical properties, and the fractured surface is analyzed through the scanning electron microscope. The addition of hybrid fillers enhances the fiber-matrix bonding strength and improves the thermal and mechanical properties up to a specific limit. Thermal gravimetric analysis was conducted to understand the thermal behavior of composite. The results revealed that the addition of filler improved the thermal stability of the composites.
\end{abstract}

\section{Introduction}

In recent years, polymer-based materials have attained substantial consideration in the fabrication of newer materials for higher appreciable electronics [1], packaging [2], and building applications. Mainly, epoxy resins have gained more interest owing to their better basic and functional properties. Epoxy-based polymers are the thermosetting resins widely used in developing advanced materials owing to their outstanding properties, including durability, stiffness, low toxicity, and lightweight with lower cost. Herein, excellent insulation with better cohesion properties of epoxy makes them recommend efficient material for insulation packing purposes. These resins are employed in various industrial applications that too mainly in the transport industries. Conversely, the stiffness of epoxy resin primarily depends on the existence of crosslinking density. Still, the occurrence of higher crosslink density might lead to the formation of brittle fracture with minor deformations $[3,4]$.

In recent days, many material scientists consider glass fibers as better reinforcement to improve epoxy resin properties due to their superior thermal, mechanical, and electrical properties. These synthetic fibers have better mechanical strength that includes elasticity with low weight. Glass fiber 
delivers better thermal properties with a high tensile strength that led to the improvement in its more comprehensive range of applications and are also considered as the candidate material to use as reinforcement in composites. Glass fibers have better thermal stability and dimensional stability that initiates their usage in various technological applications $[5,6]$. In the last few years, material researchers focus on developing advanced materials to decrease fuel [7-10] consumption in transport industries [11-13]. Hence, incorporation of these fibers in polymer material will confidently improvise the stiffness, flexibility, and strength. The combination of epoxy/glass fiber composites is also majorly used in the electronic industry in developing printed circuit boards. However, the usage of glass fiber in a polymer matrix showcases poor interfacial bonding. This fact results in the interface problem and led to crack formation and composite failures. The matrix or the polymer transfers the applied load over the fibers herein; lower interfacial bonding results in composite failure. Hence, the enhancement of interfacial bonding is a challenging task for researchers. Various methods have been adopted to improve interfacial attraction bonding among the reinforcement and matrix, such as coating and chemical grafting $[14,15]$. Among the various techniques, nanofiller usage is considered a better way to improvise the matrix's toughness and strength without compromising its essential properties. It already has proven that the incorporation of metallic, metal oxide, carbon derivate material, and ceramic material increases base matrix material's mechanical, and thermal stability.

Conversely, to attain a satisfactory thermal strength level, a higher percentage of filler materials are needed; however, it will decrease the mechanical properties. Usage of hybrid filler materials gains recent attention in improving composite materials' functional properties by combining inorganic and organic materials. Carbon-based material such as CNT, graphene, and nitride-based material such as boron nitride has many properties to enhance composite material's basic and functional properties [16-18]. In recent days, various ceramic materials have been added to epoxy resin to fabricate electrically insulative epoxy-based polymer matrix composites [19-21].

The high filler loading was essential to attain the preferred thermal properties with a sudden failure in composite mechanical strength. Among carbon base fillers, graphene is considered a better nanomaterial with high thermal properties than CNT. Some researchers found that the incorporation of graphene in a neat epoxy showcases better strength [22]. However, higher electrical conductivity and cost limit the graphene-based fillers in developing composites for electronic packaging industries where electrical insulation is needed $[23,24]$.

Synthesis of graphene is relatively expensive and complex; furthermore, extraordinary efforts must be made to attain an inexpensive method to make graphene and its related derivatives materials. The graphene family includes graphene oxide, graphene nanosheet, graphene nanoplatelet, reduced graphene oxide, and multilayered graphene. Among them, the synthesis of graphene oxide is considered a more accessible and cheaper way compared with graphene. GO has a single atomic layer synthesis by oxidation and exfoliation of graphite flakes, abundant, and low cost.

$\mathrm{GO}$ is an exfoliated form of graphene, with oxygen-based functional groups and easily dispersed in water. GO was used as the additive for various polymers that improvise the tensile strength, electrical, and thermal properties of base matrix material [25-28]. There are few types of research in which hybrid fillers are used to improve epoxy resin properties. In this, graphene-based fillers are used to improve the interfacial compatibility of polymer glass fiber composites. The hand layup method was adopted to fabricate polymer matrix composite with graphene filler (up to 1 wt.\%).

Further, the developed composite was processed under saline water ageing to improve its potential application in marine-based applications. Observations depict that incorporating graphene fillers up to $0.5 \mathrm{wt} . \%$ increases the developed composite's thermomechanical properties and found that graphene addition hinders the composite's water absorption capability $36.3 \%$ [29].

The adopted compression moulding method developed graphene filler (up to $0.7 \mathrm{wt} . \%$ ) reinforced epoxy glass fiber composite and examined the composites' thermomechanical properties. Results revealed that graphenes add up to 0.5 wt.\% increases the flexural modulus and flexural strength modulus up to $20 \%$ and $21.1 \%$ [30]. Boron nitride was used as filler material by Tang and coworkers to develop epoxyglass fiber composite by using a hot compression method and investigates its thermomechanical behavior. Results depict that BN's addition increases the thermal behavior and $7 \%$ improvement in flexural strength [31]. Ren and coworkers used a hybrid form of graphene-boron nitride nanosheet to develop epoxy composite to enhance its functional properties. Results depict that loading of hybrid filler up to $5 \mathrm{wt}$.\% showcases significant improvement in its thermal conductivity (140\%) and electrically insulation in developed composite [32]. The adopted compression moulding method developed epoxy composite with a varying percentage of graphene oxide and a constant titanium dioxide percentage [33, 34]. The research group observed that the incorporation of hybrid filler exhibits significant improvement in its thermomechanical properties. Additions of hybrid filler display a 59\% increment in tensile behavior and $79 \%$ improvement in flexural strength while relating with neat epoxy resin [35].

A clear-cut literature survey incorporating hybrid filler material in the epoxy matrix promotes better interfacial bonding between matrix and reinforcement. Usage of graphene oxide and boron nitride in the polymer matrix exhibits better improvement in matrix material's thermomechanical properties. Researchers have investigated various combinations of hybrid fillers; however, there are limited studies on incorporating graphene oxide and boron nitride in epoxy-glass fiber composite. The addition of graphene oxide up to $1 \mathrm{wt} . \%$ showcases better mechanical strength. Hence, an attempt has been made to explore the combinational influence of graphene oxide and boron nitride over epoxy glass fiber polymer matrix composites in this research. 


\section{Materials and Methods}

In this research, LY 556 grade epoxy resin and HY951 hardener $\left(\mathrm{C}_{6} \mathrm{H}_{18} \mathrm{~N}_{4}\right)$ with a gelling time of 2 to $3 \mathrm{~h}$ were selected as the base polymer matrix. The resin mentioned above and hardener combinations have unique properties such as acceptable dimensional stability and fiber impregnations with a lower viscosity range. 200 GSM, glass fiber was used as reinforcement to improvise the desirable properties of epoxy resin. Recent studies also revealed that glass fiber up to $30 \mathrm{wt} . \%$ exhibits better mechanical strength; hence, $30 \%$ of glass fiber is kept constant to develop a novel composite. Graphene oxide with an average sheet thickness of $20 \mathrm{~nm}$ was synthesis by a low-cost chemical exfoliation method, namely, modified hummer's method, and is already reported in our previous work [36]. Based on available kinds of literature, it can be depicted that the usage of GO up to $1 \mathrm{wt} . \%$ delivers excellent strength; hence 1 wt.\% of GO was set as a control sample. The same has been studies with the trial and error method, and it has been observed that above 1 wt.\% of GO expected outcome has not been attained. Different samples have been made with and without the addition of fillers and also in mono form.

Based on the observation, composite developed without filler material and with monofillers showcase lower strength while compared with hybrid filler-based composite. And the influence of the graphene derivatives was depicted in various literature states that beyond $1 \mathrm{wt} . \%$ of GO, the decremental effect has been observed for the matrix material due to its poor interfacial bonding. Hence, GO was made as a constant control sample [35, 37]. Boron nitride purchased from Sigma Aldrich was an addition filler with varying wt.\% 1, 2, 3 wt.\%. Characterization of purchased boron nitride $(\sim 1 \mu \mathrm{m})$ was already reported in our previous work [38]. Figures 1(a) and 1(b) depict the SEM images of used filler materials.

Lay-up coupled compression moulding approach was adapted to developed polymer composite. As per the research hypothesis, a measured amount of $\mathrm{GO}$ and $\mathrm{BN}$ was added to ethanol solvent, and the attained mixture was ultrasonicated for about one hour. The resultant solution was mixed with epoxy resin. To attain homogenous dispersion of hybrid filler material over resin, the mixture was stirred using mechanical stirred at the rpm of 1200 for about $2 \mathrm{~h}$. After the stirring process, the HY951 hardener was added to the mixture at the ratio of $1: 10$ and further stirred for about 5 minutes. Initially, the hand layup method was adopted for coating the attain mixture over both sides of glass fiber. $270 \times 270 \times 30 \mathrm{~mm}^{3}$ size flat mould was used for stacking the 10 layers of resincoated glass fabric. Degassing process is followed after the stacking $[39,40]$. Followed by degassing, the stacked layers were hot-pressed at $15 \mathrm{MPa}$ of pressure and further allowed for the curing process. The same procedure was used for graphene oxide-boron nitride-epoxy-glass fiber composites with a constant percentage of $\mathrm{GO}$ and varying percentage of BN $(1,2,3$ wt.\%). Some trails have been made with the combination of filler materials with glass fiber in mono form viz. 1 wt.\% GO with glass fiber and 1 wt.\% BN with glass fiber. However, the samples fabricated with the addition of filler material in mono form exhibit minimal improvement while composite fabricated hybrid filler loading. Further, this research is based on the influence of dual filler materials on polymer matrix composite mechanical behavior; hence, the combinational results of the composite under mono form have been neglected. Table 1 shows the experimental plan for composite development.

\section{Characterization of Material}

BRUKER made an X-ray diffractometer that was utilized for the confirmation of graphene oxide. Raman spectrometer (HORIBA France SAS) was used to identify the band gap and oxidation state of graphene oxide. The composite's tensile, flexural, and compressive behavior was evaluated using ASTM D 638, ASTM D 790, and ASTM D6484 standard. To investigate the flexural and tensile strength of composite, $2 \mathrm{~mm} / \mathrm{min}$ crosshead speed was adopted with a sample dimension of $135 \times 19 \times 3 \mathrm{~mm}^{3}$ (tensile test specimen) and $125 \times 13 \times 3 \mathrm{~mm}^{3}$ (flexural test specimen). To attain precise results, in this research, all the experiments were conducted three times, and average mean values were taken. JEOL JSM6610LV made scanning electron microscopy that was adopted for fracture surface analysis. Thermogravimetric analysis was carried out for the samples under the nitrogen gas atmosphere with a $20^{\circ} \mathrm{C} / \mathrm{min}$ heating rate using an alumina pan.

\section{Results}

4.1. XRD and Raman Spectrum Graphene Oxide. Figures 2(a) and 2(b) depict the XRD and Raman spectrum analysis of graphene oxide synthesis using a modified hummers method. Herein, the narrow diffraction peak at $9.3^{\circ}$ is the characteristic peak of carbon at (001). Also, the peaks reveal the presence of water molecules in between the layer of the carbon sheet and the oxygen functional group's existence. The presence of minor peaks near the range of 18 to $23^{\circ}$ indicates that synthesized graphene oxide was partially linked with oxygen atoms. Diffraction peak near $26.5^{\circ}$ is related to graphite with (002) plane and exposes an interlayer distance of graphene.

Diffraction peak at $42.2^{\circ}$ related to (100) plane with $2.12 \AA d$-spacing is evident for the successful formation of graphene oxide from graphite flakes. Raman spectrum of synthesized graphene oxide was depicted in Figure 2(b) consisting of $\mathrm{G}$ band and $\mathrm{D}$ band. This $\mathrm{G}$ band is related to the first-order scattering of carbon bonding, and the D band indicates the defects associated with grain boundaries with vacancies. Herein, $1588 \mathrm{~cm}^{-1}$ and $1351 \mathrm{~cm}^{-} 1$ are the $\mathrm{G}$ band, and the $\mathrm{D}$ band's characteristic peaks confirm the lattice distortions. The $\mathrm{D}$ band intensity mainly depends on the oxygen atom over the graphene oxide surface and the defect [41-43].

4.2. Effect of Fillers on Tensile Behavior of Composite. The experimental data collected from the tensile test of epoxy/glass fiber/GO/BN composites with different $\mathrm{BN} \%$ is plotted as Figure 3. It is clear from the plot that the ultimate tensile strength of GO filler added glass fiber reinforced epoxy 


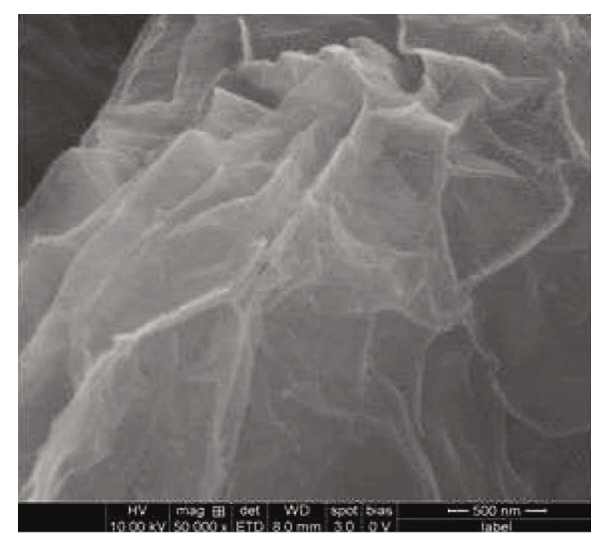

(a)

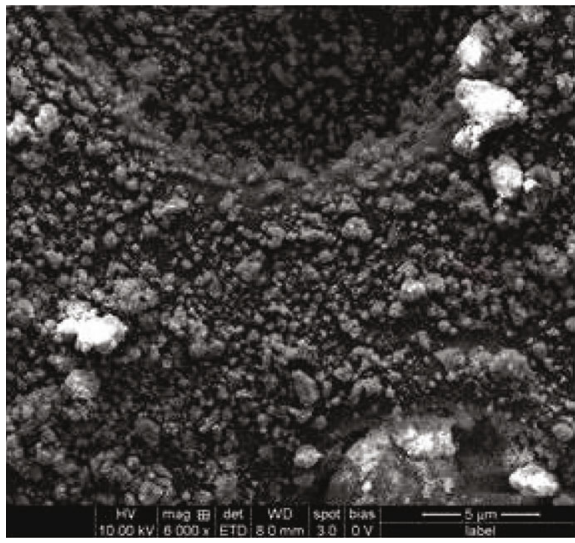

(b)

FIGURE 1: SEM of (a) graphene oxide and (b) boron nitride.

TABLE 1: Experimental plan for composite development.

\begin{tabular}{lccc}
\hline Sample & GO wt.\% & BN wt.\% & Glass fiber \\
\hline S1 & 0 & 0 & 30 \\
S2 & 1 & 1 & 30 \\
S3 & 1 & 2 & 30 \\
S4 & 1 & 3 & 30 \\
\hline
\end{tabular}

composites increases with every addition of $\mathrm{BN}$ up to $2 \%$. In contrast, the ultimate tensile strength reduces by $3 \%$ addition. Similarly, the elongation \% of the prepared composite also increases with the addition of $\mathrm{BN}$ filler. The addition of $\mathrm{BN}$ and $\mathrm{GO}$ in the composite as filler improves the bonding between reinforcement and matrix, enhancing the load transferring capability between the matrix and reinforcement.

This enhances load transferring ability results in an improvement in tensile behavior for up to $2 \%$. But an increasing percentage of $\mathrm{BN}$ addition results in property decrement, which may be due to the weakening of bonding strength due to discontinuity caused by the higher number of fillers in the matrix [44]. The addition of fillers in the matrix results in tightening the polymer matrix structure, which will also be hindered from free transferral from the polymer matrix composite $[45,46]$. On the other hand, the elongation ability of the polymer matrix is significantly reduced when added with the $\mathrm{BN}$ and GO filler materials, whereas it reduced further for every addition of BN filler, as shown in Figure 3. Elongation \% is an indicator of the ductile nature of a material, and the material which has a higher elongation percentage is termed as more ductile.

In contrast, the material with lower elongation is named brittle. In general, polymers have a modest capability to elongate, wherein the addition of fillers deduce the ductile nature and becomes more brittle for every additional BN filler. The presence of these microparticles in the polymer affects the free movement of polymer molecules. It makes it more rigid, resulting in less elongation, i.e., polymer matrix becomes more brittle.
4.3. Effect of Fillers on Flexural Behavior of Composite. Figure 4 illustrates the flexural and flexural modulus of the developed polymer matrix composite with various $\mathrm{BN}$ inclusions. $\mathrm{BN}$ and $\mathrm{GO}$ fillers in glass fiber reinforced epoxy matrix improvise the flexural modulus and strength. And the addition of BN filler up to $2 \%$ causes better flexural modulus and strength values, and accumulation of fillers over $2 \%$ results in flexural property decrement. This improvement in flexural strength is endorsed to better bonding among filler, fiber reinforcement, and matrix.

These BN particles are linked with polymer chains and form a stronger mechanical bonding that helps transfer flexural stress through the links to other chains. Due to this process, if one chain fallouts due to applied load, the others link will support composite material structure. By this fact, the damages of whole samples might be controlled. Entanglement of filler material over epoxy chain forms hurdles for moving of chains at external load. The polymer chain entanglement is initiating from the weak interfaces between matrix and reinforcement that improvise the flexural strength [47]. These $\mathrm{BN}$ particles have the mechanical interlocking characteristic that enhances interfacial adhesion between reinforcements and matrix, increasing flexural strength [48, 49].

Further, this filler material is efficient in acting as a coupling agent for organic and inorganic functional groups in advanced composite; this fact increases the molecular interactions between the matrix and reinforcement. Improvement in flexural strength is also owing to the uniform dispersion of fillers over the matrix. The addition of $\mathrm{BN}$ filler above $2 \%$ exhibits a decremental trend in flexural strength compared with a composite made with 2 wt.\% filler. The addition of $\mathrm{BN}$ particles firmly holds the glass fabric layers that increase the flexural strength of composite; however, the addition of filler material above 2 wt.\% exhibits decremental flexural strength that might be owing to agglomeration of $\mathrm{BN}$ $[50,51]$. This cluster formation increases the collision of the particles during the sonication process. This fact increases the viscosity of matrix and hybrid filler suspension and creates inferior wetting among them. Likewise, higher loading of BN (above 2 wt.\%) increases the Van der Waals forces among the resin and filler material that results in poor 


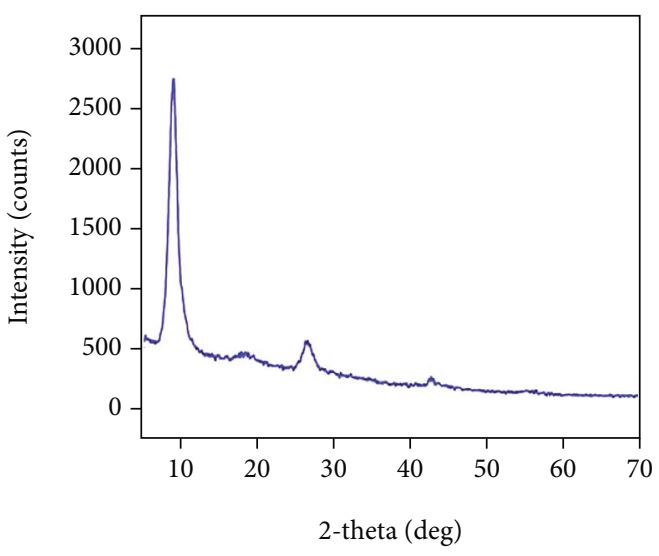

(a)

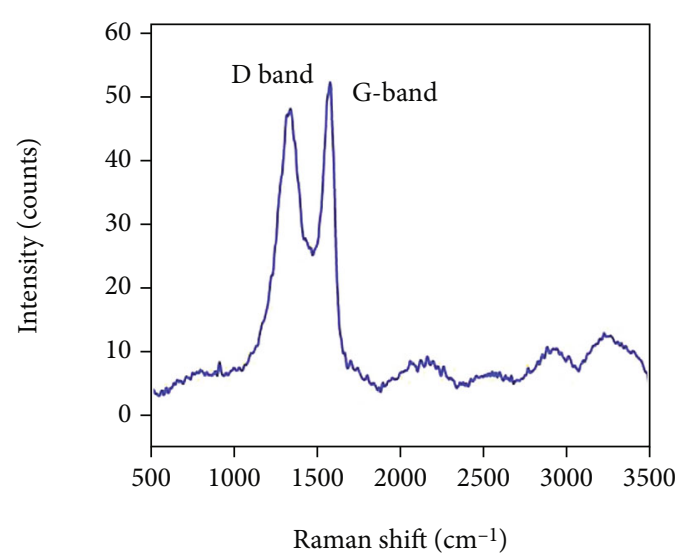

(b)

FIGURE 2: Graphene oxide: (a) XRD and (b) Raman spectrum.

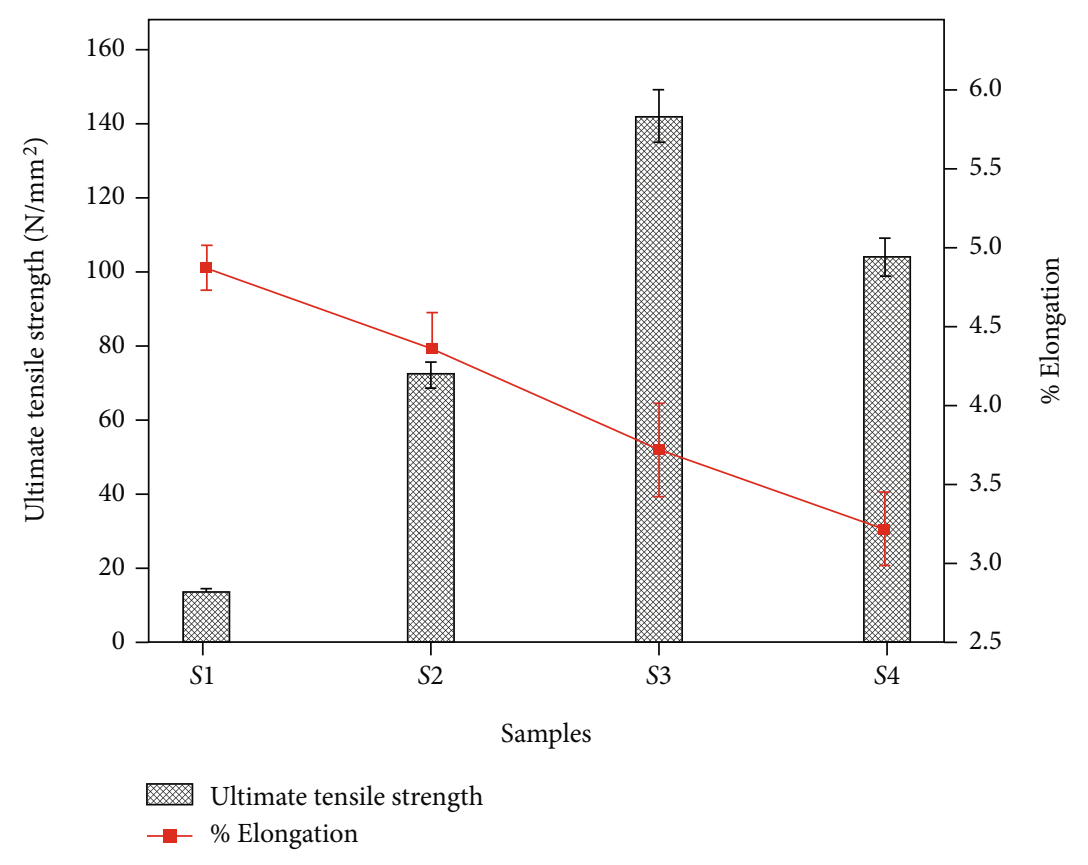

FIgURE 3: Tensile behavior of advanced composite.

dispersion; this fact decreases the flexural strength of the advanced composite. Flexural modulus, which is calculated from the flexural load versus displacement curve [52], also increases for every addition of BN fillers up to $2 \%$, and further addition of BN fillers results in the decrement of flexural modulus. The added fillers enhance the load transferring capability and improve the matrix and reinforcement interface, which improves the property of advanced composites.

4.4. Effect of Fillers on Compressive Behavior of Composite. The experimental results of the compression test are plotted in Figure 5, which confirms that the glass fiber reinforced epoxy composites' compressive strength improves with GO and BN fillers' addition. Significant improvement in compression strength of the composites is visible for every addition of $\mathrm{BN}$ fillers. As the reinforced $\mathrm{GO}$ and $\mathrm{BN}$ fillers have more rigidity and compressive strength than the polymer matrix, it gives better resistance to the compressive force.

The load-carrying ability of the added fillers results in the enhancement of the compression behavior of the epoxy matrix. The added BN and GO particles fill the voids and space between the chains of polymers created during polymerization, increasing stiffness and reducing strain. Further, bonding between the polymer matrix and fiber plays a vital role in compression strength. The addition of hybrid fillers enhances the bonding strength between the matrix and fiber, which improves compressive strength [53].

4.5. Fracture Surface Morphology of Developed Composite. Figures 6(a)-6(d) show the fractured surface of the polymer matrix composites, which helps to identify the fracture system. Figures 6(a) and 6(b) that belongs to the polymer 


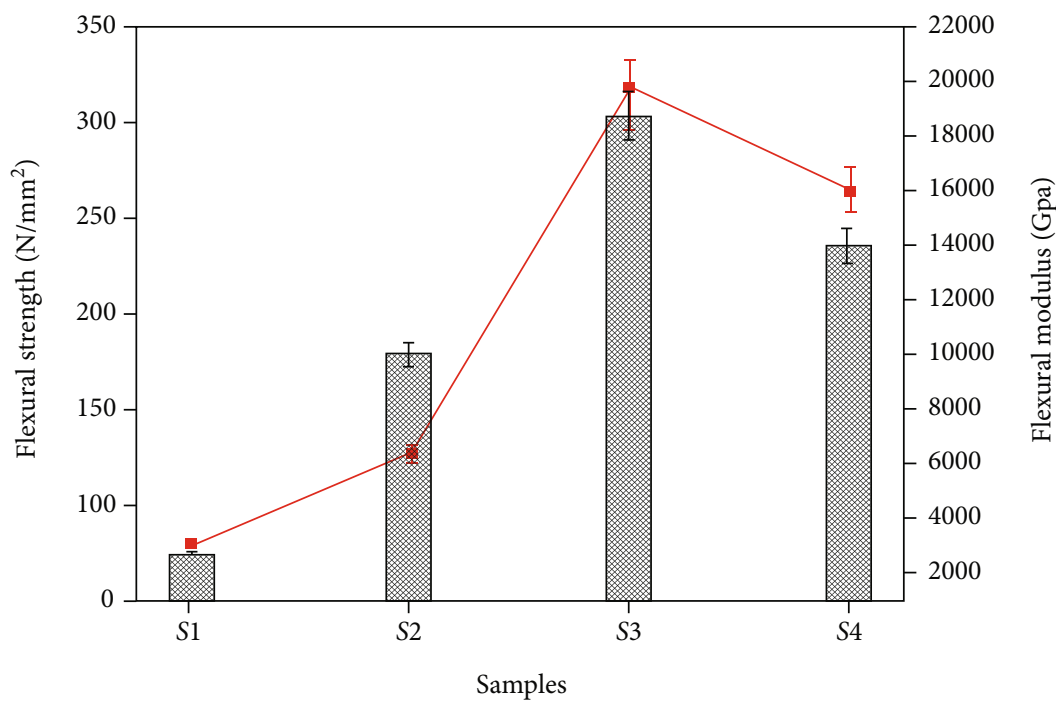

Flexural strength

$\rightarrow$ Flexural modulus

Figure 4: Flexural behavior of advanced composite.

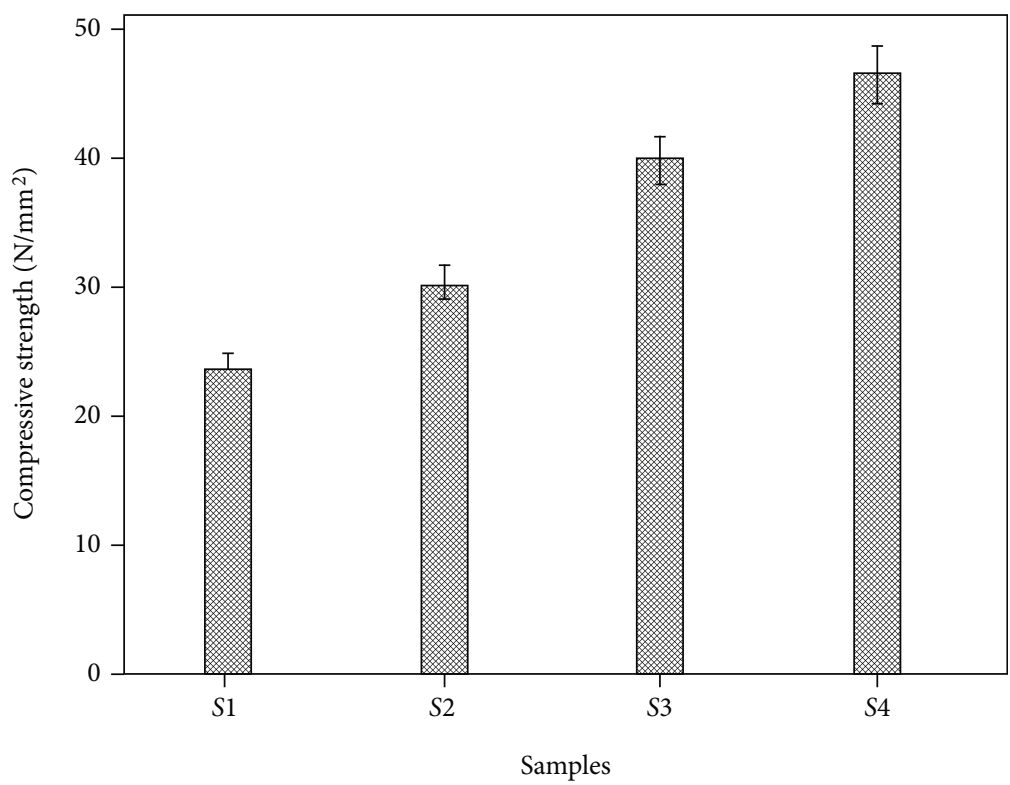

Figure 5: The compression strength of the developed composite.

composites without filler material clearly shows the fiber debonding from the matrix. This shows the lack of interface strength between the matrix and reinforced fiber which leads to uncomplicated fracture of the material, and hence, the load required to deformation is more minor, i.e., strength decreases. This less bonding between the fiber and matrix results in large fiber pull out and consequently less resistance to fracture. Figure 6(c) is belonging to the fractures surface of the 1 wt.\% BN filler added polymer composite. It also shows the EDS results of the same developed composite, which confirms the presence of fillers.

The fractured surface of the filler reinforced polymer composite shown in Figures 6(c) and 6(d) indicates the adhesion's improvement between the fiber and the matrix. Stick- ing of matrix and filler materials can be visualized from the filler's fractured surface added PMCs shown in Figures 6(c) and $6(\mathrm{~d})$. This improvement in bonding between the composites constitutions results in improved strength. On the other hand, the fibers pulled out from the matrix are clean, and there are hardly some materials stuck over the fibers, as shown in Figure 6(b), which is a fractured surface of the PMC without fillers. The crack formed at the plastic deformation's initial stage has to cross the numerous fillers and fiber-matrix interfaces that hinder the crack propagation. The fillers' hindrance forces the crack to change the direction, which increases crack length, or the fillers have to be fractured during cracking, requiring a large amount of energy. So, the incorporation of $\mathrm{BN}$ and GO fillers over 


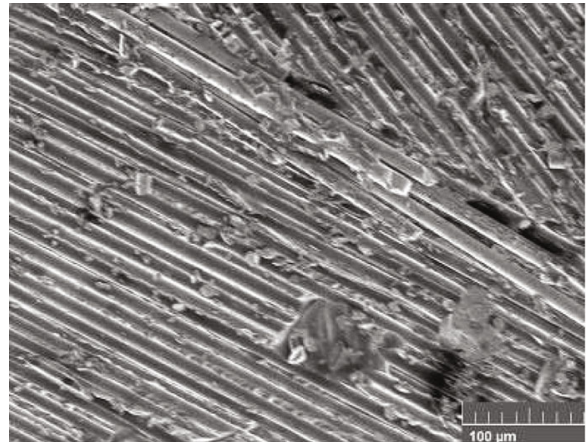

(a)

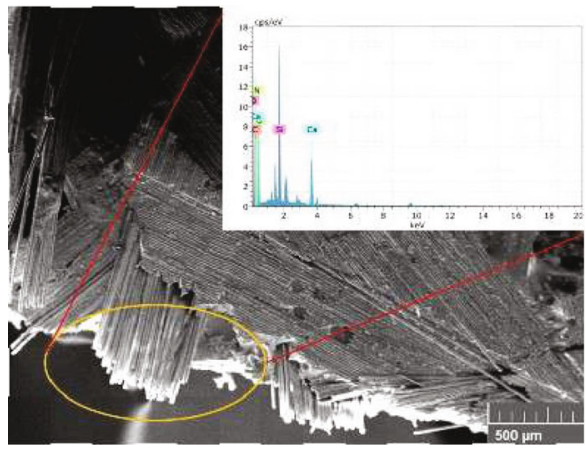

(c)

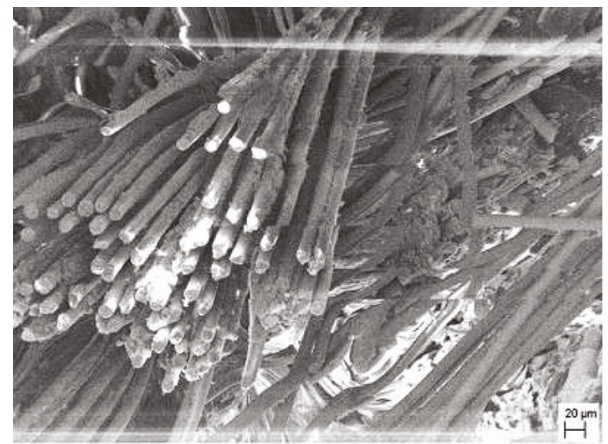

(b)

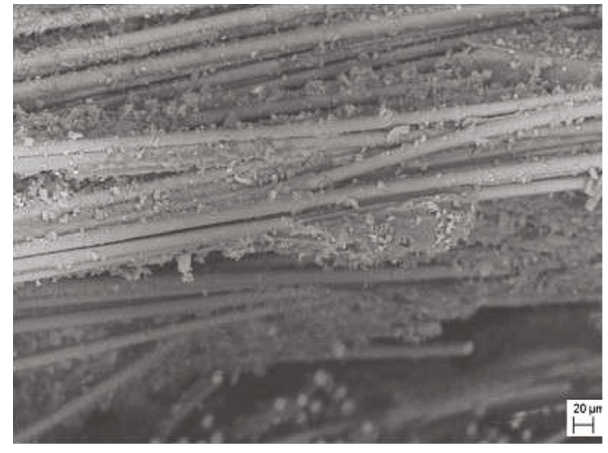

(d)

FIGURE 6: SEM of composite fracture surface: (a and b) S1; (c) S2; (d) S3.

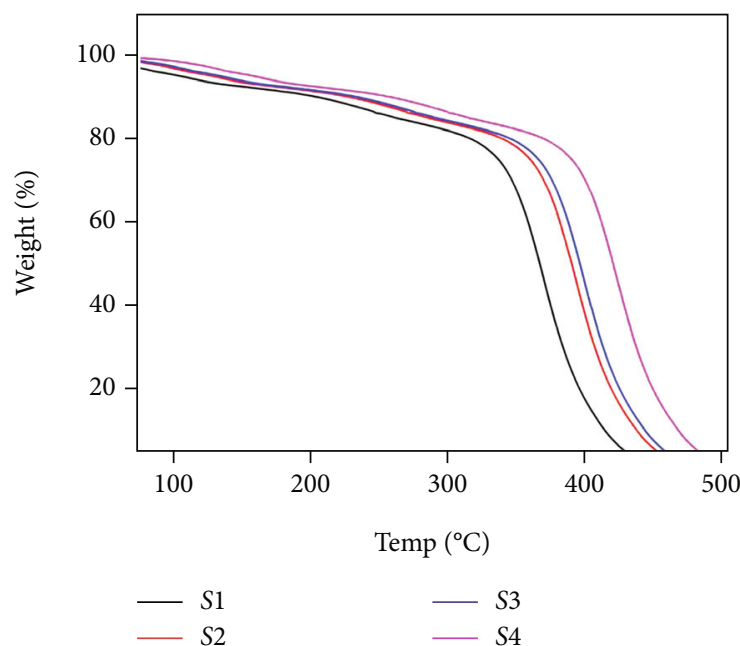

Figure 7: Thermogravimetric analysis of $S 1, S 2, S 3$, and $S 4$ composites.

glass fiber-epoxy polymer composites results in improved strength $[31,35,54]$.

4.6. Effect of Fillers on Thermal Stability of Developed Composite. The thermal behavior of GO and BN was carried out by adopting thermal gravimetric analysis. Figure 7 showed the thermal stability of composites for incorporating filler material addition with varying weight percentages. Thermogravimetric analysis was conducted between 50 and $600^{\circ} \mathrm{C}$, and attained weight percentage is reported. It can be visualized from Figure 7 that the addition of filler material in matrix material increases the thermal stability while compared with the sample $S 1$ with nil filler addition. Herein, the base sample $(S 1)$ thermal degradation occurs from 50 to $340^{\circ} \mathrm{C}$ at a mass loss of $29 \%$.

Further, the mass loss is minimal for an increasing percentage of filler material. For the sample (S4) with higher filler loading, thermal degradation occurs after $420^{\circ} \mathrm{C}$. This may be due to the hindering effect of hybrid filler material that confines the polymer chain decomposition and movement. Likewise, thermal stability is higher for the samples with higher loading of filler material. It was due to the incorporation of higher stable filler materials, viz. GO and BN.

\section{Conclusions}

Glass fiber reinforced epoxy matrix composite with hybrid $\mathrm{GO}$ and BN fillers are fabricated through compression moulding and analyzed for tensile, flexural, and compressive properties. XRD and Raman spectroscopy results depict the proper exfoliations of GO through low cost modified hummers approach. The hybrid GO, and BN filler's addition improves the epoxy matrix composite's tensile properties by enhancing the load transfer efficiency and interface strength. The total order of $\mathrm{BN}$ wt.\% results in a decremental trend in elongation of the developed composite up to $\sim 31 \%$. Higher addition of $\mathrm{BN}$ fillers over $2 \%$ resulted in decreased tensile and flexural strength due to particle aggregation and poor bonding. Developed polymer composite becomes more brittle for every addition of $\mathrm{BN}$ filler due to hindrance in molecule movement. Compression strength increases with GO and BN fillers' addition, whereas it increases with every BN 
addition. The thermal stability increases with the addition of the fillers. The incorporation of hybrid filler increases the thermal stability of the developed composite. The developed composite may use in making bumpers, blades, pump housings, motor covers, and developing structural parts in aircraft.

\section{Data Availability}

The data used to support the findings of this study are included in the article. Conflicts of Interest.

\section{Conflicts of Interest}

The authors declare that there is no conflict of interest regarding the publication of this article.

\section{References}

[1] Q. Li, J. Zhao, B. He, and Z. Hu, "Solution Processable poly(vinylidene fluoride)-based Ferroelectric Polymers for Flexible Electronics," APL Materials, vol. 9, no. 1, article 010902, 2021.

[2] F. P. La Mantia, M. Ceraulo, P. Testa, and M. Morreale, "Biodegradable polymers for the production of nets for agricultural product packaging," Materials (Basel), vol. 14, no. 2, pp. 323410, 2021.

[3] D. Margoy, I. Gouzman, E. Grossman, A. Bolker, N. Eliaz, and R. Verker, "Epoxy-based shape memory composite for space applications," Acta Astronautica, vol. 178, pp. 908-919, 2021.

[4] L. Verma, J. Andrew, S. M. Sivakumar, G. Balaganesan, S. Vedantam, and H. N. Dhakal, "Ballistic impact behaviour of glass/epoxy composite laminates embedded with shape memory alloy (SMA) wires," Molecules, vol. 26, no. 1, p. 138, 2021.

[5] P. Morampudi, K. K. Namala, Y. K. Gajjela, M. Barath, and G. Prudhvi, "Review on glass fiber reinforced polymer composites," Materials Today: Proceedings, vol. 43, pp. 314-319, 2021.

[6] T. P. Sathishkumar, S. Satheeshkumar, and J. Naveen, "Glass fiber-reinforced polymer composites - a review," Journal of reinforced plastics and composites, vol. 33, no. 13, pp. 12581275, 2014.

[7] D. Singh, R. Chaudhary, and A. Karthick, "Review on the progress of building-applied/integrated photovoltaic system," Environmental Science and Pollution Research, no. article 15349, 2021.

[8] R. Naveenkumar, M. Ravichandran, B. Stalin et al., "Comprehensive review on various parameters that influence the performance of parabolic trough collector," Environmental Science and Pollution Research, vol. 28, no. 18, article 13439, pp. 22310-22333, 2021.

[9] V. Rajendran, H. Ramasubbu, K. Alagar, and V. K. Ramalingam, "Performance analysis of domestic solar air heating system using V-shaped baffles - an experimental study," Proceedings of the Institution of Mechanical Engineers, Part E: Journal of Process Mechanical Engineering, 2021.

[10] U. Muthuraman, R. Shankar, V. K. Nassa et al., "Energy and Economic Analysis of Curved, Straight, and Spiral Flow FlatPlate Solar Water Collector," International Journal of Photoenergy, vol. 2021, Article ID 5547274, 11 pages, 2021.
[11] M. Mohamed, S. Brahma, H. Ning, and S. Pillay, "Development of beneficial residual stresses in glass fiber epoxy composites through fiber prestressing," Journal of Reinforced Plastics and Composites, vol. 39, no. 13-14, pp. 487-498, 2020.

[12] R. Kattaguri, A. O. Fulmali, R. K. Prusty, and B. C. Ray, "Effects of acid, alkaline, and seawater aging on the mechanical and thermomechanical properties of glass fiber/epoxy composites filled with carbon nanofibers," Journal of Applied Polymer Science, vol. 137, no. 10, article 48434, 2020.

[13] J. A. Rojas, B. Ribeiro, and M. C. Rezende, "Influence of serrated edge and rectangular strips of MWCNT buckypaper on the electromagnetic properties of glass fiber/epoxy resin composites," Carbon N. Y., vol. 160, pp. 317-327, 2020.

[14] M. Taşyürek and M. Kara, "Low-velocity impact response of pre-stressed glass fiber/nanotube filled epoxy composite tubes," Journal of Composite Materials, vol. 55, no. 7, pp. 915-926, 2021.

[15] G.-F. Wang, W. Zhou, Y.-J. Zhang, and K.-N. Han, "Flexural damage and failure behavior of glass fiber epoxy composites repaired by patch embedded with $\mathrm{ZnO}$ whiskers," Journal of Adhesion Science and Technology, vol. 34, no. 14, pp. 15261543, 2020.

[16] H. N. Yoon, D. Jang, H. K. Lee, and I. W. Nam, "Influence of carbon fiber additions on the electromagnetic wave shielding characteristics of CNT-cement composites," Construction and Building Materials, vol. 269, article 121238, 2021.

[17] S. Wang, H. Xue, S. Guo et al., "Graphene/nanorubber reinforced electrically conductive epoxy composites with enhanced toughness," Journal of Applied Polymer Science, vol. 138, no. 14, article 50163, 2021.

[18] V. Kavimani, K. Soorya Prakash, and M. Arun Pandian, "Influence of r-GO addition on enhancement of corrosion and wear behavior of AZ31 MMC," Applied Physics A: Materials Science \& Processing, vol. 123, no. 8, p. 514, 2017.

[19] A. Tarhini, A. Tehrani-Bagha, M. Kazan, and B. Grady, "The effect of graphene flake size on the properties of graphenebased polymer composite films," Journal of Applied Polymer Science, vol. 138, no. 6, article e49821, 2021.

[20] B. Tale, K. R. Nemade, and P. V. Tekade, "The Comprehensive study of Titanium oxide doped Conducting polymers nanocomposites for Photovoltaic applications," Polymer-Plastics Technology and Materials, pp. 1-10, 2021.

[21] A. Chouhan, T. K. Sarkar, S. Kumari, K. L. N. Sivakumar, H. Sugimura, and O. P. Khatri, "Mechano-adaptive thin film of graphene-based polymeric nanocomposite for enhancement of lubrication properties," Applied Surface Science, vol. 538, article 148041, 2021.

[22] N. T. Kamar, M. M. Hossain, A. Khomenko, M. Haq, L. T. Drzal, and A. Loos, "Interlaminar reinforcement of glass fiber/epoxy composites with graphene nanoplatelets," Composites. Part A, Applied Science and Manufacturing, vol. 70, pp. 82-92, 2015.

[23] X. Bai, C. Zhang, X. Zeng, L. Ren, R. Sun, and J. Xu, “Recent progress in thermally conductive polymer/boron nitride composites by constructing three-dimensional networks," Composites Communications, vol. 24, article 100650, 2021.

[24] Y. Mussa, Z. Bayhan, N. Althubaiti, M. Arsalan, and E. Alsharaeh, "Hexagonal boron nitride effect on the performance of graphene-based lithium- sulfur batteries and its stability at elevated temperatures," Materials Chemistry and Physics, vol. 257, article 123807, 2021. 
[25] H. Nosrati, R. Sarraf-Mamoory, M. Canillas Perez, D. Q. S. le, R. Zolfaghari Emameh, and C. E. Bünger, "Characteristics of hydroxyapatite-reduced graphene oxide composite powders synthesized via hydrothermal method in the absence and presence of diethylene glycol," Open Ceramics, vol. 5, article 100067, 2021.

[26] M. Tudose, E. M. Anghel, E. N. Hristea et al., "Benzofurazan derivatives modified graphene oxide nanocomposite: Physicochemical characterization and interaction with bacterial and tumoral cells," Materials Science and Engineering: C, vol. 123, article 112028, 2021.

[27] D. C. Marcano, D. V. Kosynkin, J. M. Berlin et al., "Improved synthesis of graphene oxide," ACS nano, vol. 4, no. 8, pp. 4806-4814, 2010.

[28] J. Chen, M. Perez-Page, Z. Ji, Z. Zhang, Z. Guo, and S. Holmes, "One step electrochemical exfoliation of natural graphite flakes into graphene oxide for polybenzimidazole composite membranes giving enhanced performance in high temperature fuel cells," Journal of Power Sources, vol. 491, article 229550, 2021.

[29] A. Anand, S. K. Ghosh, A. O. Fulmali, and R. K. Prusty, "Enhanced barrier, mechanical and viscoelastic properties of graphene oxide embedded glass fibre/epoxy composite for marine applications," Construction and Building Materials, vol. 268, article 121784, 2021.

[30] R. K. Prusty, S. K. Ghosh, D. K. Rathore, and B. C. Ray, "Reinforcement effect of graphene oxide in glass fibre/epoxy composites at in- situ elevated temperature environments: An emphasis on graphene oxide content," Composites. Part A, Applied Science and Manufacturing, vol. 95, pp. 40-53, 2017.

[31] L. Tang, M. He, X. Na et al., "Functionalized glass fibers cloth/spherical BN fillers/epoxy laminated composites with excellent thermal conductivities and electrical insulation properties," Composites Communications, vol. 16, pp. 5-10, 2019.

[32] J. Ren, Q. Li, L. Yan et al., "Enhanced thermal conductivity of epoxy composites by introducing [email protected] nitride nanosheets hybrid nanoparticles," Materials and Design, vol. 191, article 108663, 2020.

[33] K. Yoganandam, V. Shanmugam, A. Vasudevan et al., "Investigation of Dynamic, Mechanical, and Thermal Properties of Calotropis Procera Particle-Reinforced PLA Biocomposites," Advances in Materials Science and Engineering, vol. 2021, Article ID 2491489, 7 pages, 2021.

[34] R. Dharmaraj, A. Karthick, G. K. Arunvivek et al., "Novel Approach to Handling Microfiber-Rich Dye Effluent for Sustainable Water Conservation," Advances in Civil Engineering, vol. 2021, Article ID 1323472, 10 pages, 2021.

[35] V. Kavimani, K. Soorya Prakash, T. Thankachan, and R. Udayakumar, "Synergistic improvement of epoxy derived polymer composites reinforced with Graphene Oxide (GO) plus Titanium di oxide $\left(\mathrm{TiO}_{2}\right)$," Composites. Part B, Engineering, vol. 191, article 107911, 2020.

[36] K. V, S. P. K, R. R et al., "Electrodeposition of $\mathrm{r}-\mathrm{GO} / \mathrm{SiC}$ nanocomposites on magnesium and its corrosion behavior in aqueous electrolyte," Applied Surface Science, vol. 424, pp. 63-71, 2017.

[37] N. I. C. Berhanuddin, I. Zaman, S. A. M. Rozlan et al., "Enhancement of Mechanical Properties of Epoxy/Graphene Nanocomposite," in Journal of Physics: Conference Series, vol. 94, p. 12036, Langkawi, Malaysia, 2017.

[38] T. Thankachan, K. S. Prakash, and V. Kavimani, "Investigating the effects of hybrid reinforcement particles on the microstructural, mechanical and tribological properties of friction stir processed copper surface composites," Composites. Part B, Engineering, vol. 174, article 107057, 2019.

[39] B. Stalin, M. Ravichandran, G. T. Sudha et al., "Effect of titanium diboride ceramic particles on mechanical and wear behaviour of $\mathrm{Cu}-10 \mathrm{wt} \% \mathrm{~W}$ alloy composites processed by P/M route," Vacuum, vol. 184, article 109895, 2021.

[40] S. D. Kumar, M. Ravichandran, A. Jeevika, B. Stalin, C. Kailasanathan, and A. Karthick, "Effect of $\mathrm{ZrB}_{2}$ on microstructural, mechanical and corrosion behaviour of aluminium (AA7178) alloy matrix composite prepared by the stir casting route," Ceramics International, vol. 47, no. 9, pp. 1295112962, 2021.

[41] A. Jabbar, G. Yasin, W. Q. Khan et al., "Electrochemical deposition of nickel graphene composite coatings: effect of deposition temperature on its surface morphology and corrosion resistance," RSC Advances, vol. 7, no. 49, pp. 31100-31109, 2017.

[42] L. Stobinski, B. Lesiak, A. Malolepszy et al., "Graphene oxide and reduced graphene oxide studied by the XRD, TEM and electron spectroscopy methods," Journal of Electron Spectroscopy and Related Phenomena, vol. 195, pp. 145-154, 2014.

[43] F. T. Johra, J.-W. Lee, and W.-G. Jung, "Facile and safe graphene preparation on solution based platform," Journal of Industrial and Engineering Chemistry, vol. 20, no. 5, pp. 2883-2887, 2014.

[44] S. R. Benin, S. Kannan, A. J. Moses, and R. J. Bright, "Mechanical characterization of prosopis juliflora reinforced polymer matrix composites with filler material," Materials Today: Proceedings, vol. 33, pp. 1110-1115, 2020.

[45] U. Konwar, G. Das, and N. Karak, “Mesua ferrea L. Seed oil based highly branched polyester/epoxy blends and their nanocomposites," Journal of Applied Polymer Science, vol. 121, no. 2, pp. 1076-1085, 2011.

[46] B. M. Reddy, R. M. Reddy, D. M. S. Reddy, N. Ananthakrishna, and P. V. Reddy, "Development and characterisation of Cordia dichotoma fibre/granite filler reinforced polymer blended (epoxy/polyester) hybrid composites," Advances in Materials and Processing Technologies, pp. 1-17, 2020.

[47] Y. S. Rao, N. S. Mohan, N. Shetty, and B. Shivamurthy, "Effects of solid lubricant fillers on the flexural and shear strength response of carbon fabric-epoxy composites," Polymer Testing, vol. 96, article 107085, 2021.

[48] K. S. A. Ali, V. Mohanavel, M. Ravichandran, S. Arungalai Vendan, T. Sathish, and A. Karthick, "Microstructure and Mechanical Properties of Friction Stir Welded SiC/TiB2 Reinforced Aluminum Hybrid Composites," Silicon, no. article 1114, 2021.

[49] T. Sathish, V. Mohanavel, A. Karthick, M. Arunkumar, M. Ravichandran, and S. Rajkumar, "Study on Compaction and Machinability of Silicon Nitride (Si3N4) Reinforced Copper Alloy Composite through P/M Route," International Journal of Polymer Science, vol. 2021, Article ID 7491679, 10 pages, 2021.

[50] G. Navaneethakrishnan, T. Karthikeyan, S. Saravanan, and V. Selvam, "Influence of boron nitride on morphological, mechanical, thermal and wear characteristics of epoxy nanocomposites," Materials Research Innovations, vol. 24, no. 5, pp. 257-262, 2020.

[51] M. G. Rasul, A. Kiziltas, C. D. Malliakas et al., "PolyethyleneBN nanosheets nanocomposites with enhanced thermal and mechanical properties," Composites Science and Technology, vol. 204, article 108631, 2021. 
[52] T. P. Sathishkumar and S. Ramakrishnan, "Mechanical Properties of Nanococonut Shell Filler Mixed Jute Mat-Reinforced Epoxy Composites for Structure Application," Fiber-Reinforced Nanocomposites: Fundamentals and Applications, pp. 459-476, 2020.

[53] V. Kavimani, B. Stalin, P. M. Gopal, M. Ravichandran, A. Karthick, and M. Bharani, "Application of r-GO-MMT hybrid nanofillers for improving strength and flame retardancy of epoxy/glass fibre composites," Advances in Polymer Technology, vol. 2021, Article ID 6627743, 9 pages, 2021.

[54] J. S. Jayan, K. Pal, A. Saritha, B. D. S. Deeraj, and K. Joseph, "Graphene oxide as multi-functional initiator and effective molecular reinforcement in PVP/epoxy composites," Journal of Molecular Structure, vol. 1230, article 129873, 2021. 